\title{
Cuidar em Oncologia: Desafios e Superações Cotidianas Vivenciados por Enfermeiros
}

https://doi.org/10.32635/2176-9745.RBC.2019v65n3.818

\author{
Caring in Oncology: Challenges and Daily Overcoming Experienced by Nurses \\ Cuidar en Oncología: Desafíos y Superacciones Cotidianas Vivenciados por Enfermeros
}

\author{
Raphaela Amanda Louise de Oliveira do Carmo'; Andreia Guerra Siman²; Renata Almeida de Matos ${ }^{3}$; Érica Toledo de Mendonça ${ }^{4}$
}

\begin{abstract}
Resumo
Introdução: $\mathrm{O}$ cuidar em Oncologia é algo complexo. Os profissionais que atuam nessa área frequentemente são submetidos a fatores de riscos emocionais, exigindo deles habilidades para lidar com os sentimentos dos outros e com as suas próprias emoçóes frente ao cuidado oncológico e seus desafios. Objetivo: Compreender a perspectiva de enfermeiros acerca do processo de enfrentamento dos desafios vivenciados no cuidado à pessoa com câncer. Método: Pesquisa de natureza qualitativa, realizada em um hospital oncológico do interior de Minas Gerais, junto a enfermeiros dessa instituição. A coleta de dados foi realizada por um roteiro com perguntas abertas, e se encerrou no momento em que se constatou a saturação dos dados que foram analisados pela técnica de Análise de Conteúdo. Resultados: Foram entrevistados 13 enfermeiros, cujos depoimentos originaram três categorias: a primeira discorre sobre o cotidiano do enfermeiro na Oncologia, apontando aspectos positivos, negativos e desafios inerentes a essa prática; a segunda categoria sinaliza para as competências atitudinais fundamentais ao processo de cuidado na Oncologia, como empatia, humanização, carinho, acolhimento, maturidade, força e paciência; e a terceira apresenta como superação importante na prática do enfermeiro saber lidar com a questáo emocional, além das formas de enfrentamento utilizadas por esse profissional para sustentar suas ações cotidianas. Conclusáo: Os resultados apontam que é necessário (re)conduzir um novo olhar à formação de profissionais de saúde, para além das competências técnicas, sinalizando para a relevância da formação centrada em competências humanas e relacionais, indispensáveis ao processo de trabalho no âmbito da Oncologia. Palavras-chave: Oncologia; Enfermagem Oncológica; Competência Profissional; Resiliência Psicológica.
\end{abstract}

\begin{abstract}
Introduction: Caring in Oncology is quite complex. Professionals working in this area are often subject to emotional risk factors, demanding from them skills to cope with the feelings of the others and with their own emotions in face of the oncologic care and its challenges. Objective: To understand the nurses' perspective about the process of coping with the challenges experienced while caring for the person with cancer. Method: Qualitative study, performed with the nurses of a cancer hospital in the rural area of Minas Gerais. The data were collected through an open questions script and ended when the Content Analysis specialist concluded that the saturation of the data was achieved. Results: Interviews were conducted with thirteen male nurses, whose narratives gave rise to three categories: the first discusses the nurses' daily routine in Oncology, pointing out positive, negative and inherent challenges to this practice; the second category indicates the core attitudinal skills to the oncology caring process, such as empathy, humanization, affection, acceptance, maturity, strength and patience; and the third category describes how the professionals deal with the emotional issue in their practice further to their actions to support their daily routine. Conclusion: The results point out that it is necessary to envisage a new angle about the formation of health professionals further to the technical skills, emphasizing the relevance of focused coaching in human and relational capabilities that are crucial for the work process in Oncology.

Key words: Medical Oncology; Oncology Nursing; Professional Competence; Resilience, Psychological.
\end{abstract}

Resumen

Introducción: El cuidar en Oncología es algo complejo, estando los profesionales que actúan en esa área frecuentemente sometidos a factores de riesgos emocionales, exigiendo de las mismas habilidades para lidiar con los sentimientos de los demás y con sus propias emociones frente al cuidado oncológico y sus desafíos. Objetivo: Comprender la perspectiva de enfermeros acerca del proceso de enfrentamiento de los desafíos vivenciados en el cuidado a la persona con cáncer. Método: Investigación de naturaleza cualitativa, realizada en un hospital oncológico del interior de Minas Gerais, junto a enfermeros de esta institución. La recolección de datos fue realizada por un guión con preguntas abiertas, y se cerró en el momento en que se constató la saturación de los datos. Los datos fueron analizados por la técnica de Análisis de Contenido. Resultados: Fueron entrevistados trece enfermeros, cuyos testimonios originaron tres categorías: la primera discurre sobre el cotidiano del enfermero en la Oncología, apuntando aspectos positivos, negativos y desafíos inherentes a esta práctica; la segunda categoría seńala a las competencias actitudinales fundamentales al proceso de cuidado en la oncología, como empatía, humanización, cariño, acogida, madurez, fuerza y paciencia; y la tercera categoría presenta como superación importante en la práctica del enfermero saber lidiar con la cuestión emocional, además de las formas de enfrentamiento utilizadas por este profesional para sostener sus acciones cotidianas. Conclusión: Los resultados apuntan que es necesario (re) conducir una nueva mirada a la formación de profesionales de salud más allá de las competencias técnicas, señalando para la relevancia de la formación ingresada en competencias humanas y relacionales, indispensables al proceso de trabajo en el ámbito de la Oncología.

Palabras clave: Oncología Médica; Enfermería Oncológica; Competencia Profesional; Resiliencia Psicológica.

\footnotetext{
${ }^{1}$ Universidade Federal de Viçosa. Viçosa (MG), Brasil. Orcid iD: https://orcid.org/0000-0003-4391-6257

${ }^{2}$ Departamento de Medicina e Enfermagem da Universidade Federal de Viçosa. Viçosa (MG), Brasil. Orcid iD: https://orcid.org/0000-0001-79909273

${ }^{3}$ Fundação Cristiano Varella. Muriaé (MG), Brasil. Orcid iD: https://orcid.org/0000-0002-5204-7578

${ }^{4}$ Departamento de Medicina e Enfermagem da Universidade Federal de Viçosa. Viçosa (MG), Brasil. Orcid iD: https://orcid.org/0000-0002-3014-1504

Endereço para correspondência: Raphaela Amanda Louise de Oliveira do Carmo. Rua Nossa Senhora das Graças, 240 - Bom Jesus. Viçosa (MG), Brasil. CEP $36570-000$. E-mail: raphaela.oliveira@ufv.com.br
} 


\section{INTRODUÇÃO}

O câncer é uma doença de elevada incidência, sendo considerado mundialmente um problema de saúde pública. Seu diagnóstico é cercado de estigmas, medos e incertezas, acarretando mudanças fisiológicas, psicossociais e econômicas na vida do paciente e do seu núcleo familiar ${ }^{1-2}$.

As incertezas relacionadas ao câncer dizem respeito à sua evolução e aos resultados do tratamento, causando sofrimento, angústia, insegurança, dor e revolta entre os acometidos e seus familiares. Esses sentimentos despertados podem ser atribuídos à compreensão, ainda muito enraizada no senso comum, do câncer como doença que não tem cura e, muitas vezes, estigmatizado como sinônimo de morte ${ }^{3}$.

Assim, ao cuidar do paciente oncológico, os enfermeiros convivem com alto grau de comprometimento emocional ${ }^{4}$, uma vez que se deparam com indivíduos que realizam tratamentos prolongados que, diversas vezes, resultam em inúmeros efeitos colaterais e dificuldades, como alteraçôes da rotina de vida, da autoestima e da autoimagem, além de vivenciarem experiências com a finitude da vida, gerando grande impacto na sua identidade pessoal e profissional e de toda equipe envolvida no cuidado.

Diante disso, os profissionais que atuam nessa área são frequentemente submetidos a fatores de riscos emocionais, exigindo do profissional enfermeiro habilidades para lidar com os sentimentos dos outros e com as suas próprias emoçōes frente ao cuidado oncológico e seus desafios.

Nesse sentido, este estudo se justifica por contribuir para uma nova forma de olhar a assistência em saúde a partir da perspectiva dos profissionais que cuidam, além de auxiliar os profissionais que têm interesse ou que estão ingressando na área oncológica a conhecer um pouco mais do que é exigido para atuar nesse campo. Ademais, conhecer como se processa o cotidiano de trabalho dos enfermeiros na Oncologia, com foco nos desafios que se apresentam à atuação nessa área, nos fatores que eles julgam ser necessários superar no cotidiano para adequarem seu perfil a demandas exigidas, e ainda às formas de enfrentamento dos desafios que se colocam, é importante para a conformação de um perfil profissional para atuaçáo na área.

Consoante a essas questóes, no que diz respeito ao perfil profissional inscrito, as Diretrizes Curriculares Nacionais dos cursos de Enfermagem preconizam a formaçáo de um profissional generalista, formado com base no rigor científico e intelectual, pautado em princípios éticos, que atue como promotor da saúde integral do ser humano, desenvolvendo habilidades e competências relacionadas à atenção à saúde, tomada de decisões, comunicação, liderança, administração, gerenciamento e educação permanente ${ }^{6}$. Além disso, este estudo se alicerça sobre os pressupostos das competências, que compreendem um conjunto de conhecimentos, habilidades e atitudes que integram o perfil do profissional, e que se ancoram em quatro eixos: aprender a ser, aprender a conhecer, aprender a conviver junto e aprender a fazer; atributos que, em conjunto, garantem a integralidade do cuidado prestado pelo profissional da saúde ${ }^{7}$.

Frente a isso, torna-se importante investir em estudos que qualifiquem o perfil profissional em áreas específicas, como a Oncologia, de forma a orientar os enfermeiros no que tange às competências específicas que devem desenvolver frente às peculiaridades dessa área de conhecimento, além de sinalizar para aspectos importantes que podem ser abordados nos processos de formação dos enfermeiros.

Assim, as questôes que se pretende responder são: Quais os maiores desafios o enfermeiro considera vivenciar no seu cotidiano profissional no cuidado ao paciente oncológico? Quais os mecanismos de enfrentamento dos enfermeiros na assistência ao paciente oncológico?

Desse modo, o presente estudo tem como objetivo compreender a perspectiva de enfermeiros acerca do processo de enfrentamento dos desafios vivenciados no cuidado à pessoa com câncer.

\section{MÉTODO}

Pesquisa de natureza qualitativa, que tem como objeto de estudo o universo da produção humana, representado pelo mundo das relaçôes, representatividade e intencionalidade do ser humano. A abordagem qualitativa se aprofunda no mundo dos significados, motivos, aspiraçōes, crenças, valores e atitudes dos sujeitos inseridos em uma realidade social, na qual vivenciam fenômenos humanos, permitindo o aprofundamento relativo aos significados que as pessoas atribuem às suas açôes e relaçôes humanas ${ }^{8}$.

A pesquisa foi realizada em um hospital oncológico localizado no interior de Minas Gerais, credenciado junto ao Ministério da Saúde como Centro de Alta Complexidade em Oncologia (Cacon) ${ }^{9}$, contando com um número total de 56 enfermeiros.

Os participantes da pesquisa foram enfermeiros dessa instituição que aceitaram participar voluntariamente do estudo. Com relação aos critérios de inclusão, consideraram-se como inclusos os participantes que possuíam um período mínimo de seis meses de atuação na Oncologia, em qualquer setor do hospital, justificado pela necessidade de adaptação do profissional ao cotidiano de trabalho na Oncologia e à familiarização com os aspectos 
concernentes ao processo saúde-doença-adoecimento dos pacientes oncológicos. Foram excluídos do estudo os enfermeiros que tinham tempo de atuação inferior a seis meses e que estivessem de férias ou licenciados por algum motivo.

A inserção dos pesquisadores no campo se deu por intermédio da enfermeira responsável técnica do hospital, que encaminhou o entrevistador aos setores para conhecer os possíveis participantes e informar sobre os objetivos da pesquisa. A seleção dos enfermeiros nos referidos setores ocorreu de forma aleatória, a partir da manifestaçâo do interesse em participar do estudo. A coleta de dados ocorreu no mês de fevereiro de 2018, por meio de entrevista guiada por um roteiro com as seguintes perguntas abertas: Conte-me sobre o seu cotidiano de trabalho na Oncologia. Quais situaçóes você considera mais difíceis ao cuidar do paciente oncológico? Como você se sente ao lidar com essas situaçôes desafiadoras? $\mathrm{O}$ que você faz para enfrentar as dificuldades que surgem no cuidado com os pacientes oncológicos? $\mathrm{O}$ que você já superou e/ou deseja superar relacionado à sua atuação como enfermeiro da Oncologia? Você acha que o enfermeiro em Oncologia tem alguma competência ou alguma característica que o difere dos enfermeiros de outras áreas?. A coleta de dados foi interrompida quando o pesquisador constatou que sua interação com o campo não mais forneceu elementos para aprofundar a teorização da pesquisa, momento em que houve a saturação dos dados ${ }^{10}$.

Para que houvesse o registro na íntegra dos depoimentos dos participantes, foi solicitada a eles a permissão para gravação das entrevistas. $\mathrm{O}$ anonimato dos entrevistados foi garantido pela preservaçáo dos seus nomes, sendo os mesmos identificados com a letra $\mathrm{E}$ (enfermeiro) acompanhados pelo número correspondente à ordem de realização da entrevista, a saber: E1, E2, E3...

A análise das entrevistas se deu por meio da técnica de Análise do Conteúdo, que divide o processo de análise nas seguintes fases: organização da análise, codificação e categorização dos dados ${ }^{11}$. Inicialmente, realizou-se uma leitura flutuante e exaustiva do material de forma a permitir uma familiarização com o texto e obter uma compreensão sobre o que o sujeito buscava transmitir. Logo depois, foram definidas as unidades de significação, conhecidas como temas, nas quais foram identificados os elementos semanticamente semelhantes, para posterior categorização, análise e interpretação dos dados.

A pesquisa foi desenvolvida respeitando os aspectos éticos conforme a Resoluçáo 466/2012 do Conselho Nacional de Saúde, e foi aprovada pelo Comitê de Ética em Pesquisa com Seres Humanos da Universidade Federal de Viçosa sob o número CAAE: 80132517.6.0000.5153.

\section{RESULTADOS}

Dos 13 indivíduos entrevistados, a maioria (69,2\%) era do sexo feminino e a idade variou de 25 a 32 anos. $\mathrm{O}$ tempo de formação variou de um a nove anos, sendo o tempo médio igual a cinco anos de formação. Já o tempo de atuação na área de Oncologia variou de um a cinco anos, sendo que a maioria $(61,5 \%)$ dos participantes referiu ter saído da faculdade e ingressado direto na área para trabalhar.

A partir da análise dos dados, emergiram três categorias principais: o cotidiano do (Ser) enfermeiro em Oncologia; competências profissionais do enfermeiro que atua na Oncologia; e superaçôes cotidianas e formas de enfrentamento na prática assistencial do enfermeiro na Oncologia.

\section{COTIDIANO DO (SER) ENFERMEIRO EM ONCOLOGIA}

Os resultados dessa categoria revelaram que o cotidiano de trabalho na Oncologia é visto por alguns profissionais ora como negativo, ora como positivo. Alguns participantes trouxeram relatos de um cotidiano caracterizado negativamente como estressante, cansativo, pesado, maçante e carregado de sofrimento. Os depoimentos que se seguem demonstram essas questóes:

[...] é estressante, é cansativo (E1); [...] é um cotidiano bem pesado [...] os pacientes exigem muito da gente, eles sugam muito da gente (E4); [...] é uma rotina bem maçante às vezes (E9); [...] o dia a dia da gente que lida com oncologia é assim, tem muito sofrimento [...] (E3).

Pôde-se perceber também que o cotidiano desperta sentimentos negativos nos participantes, como frustração, depressão e desespero. Esses sentimentos puderam ser constatados quando os entrevistados trouxeram relatos de vivências, como o momento de falar sobre o diagnóstico da doença, assim como a sua recidiva ou progressão, se configurando em situaçóes difíceis de serem enfrentadas junto a pacientes, familiares e equipe de trabalho, podendo ser evidenciadas nos seguintes depoimentos:

[...] aquela frustaçáo de ter falado a verdade pra ele, mas eu precisava ter falado [...] eu choro com as mulheres aqui quando eu falo que elas vão perder os seios completamente (E7); [...] eu achei que ia entrar em depressão [...] eu fiquei desesperada, porque a família ficou desesperada (E8).

Sentimentos de incapacidade e impotência também surgiram na descrição dos participantes sobre o dia a dia de trabalho na Oncologia, durante os depoimentos 
que remeteram às questôes de impossibilidade de cura da doença e terminalidade, o que pode ser verificado nas seguintes falas:

[...] a principal sensação num momento assim é impotência, não tem o que eu posso fazer, não tem como eu lidar com isso, tudo o que eu posso fazer na verdade é esperar esse paciente chegar no fim (E3); [...] a parte mais difícil do cuidado é a terminalidade, quando o paciente encerra né [...] hoje ele ta aqui, amanhã esse paciente já pode não estar mais. Então assim, é uma situação difícil [...] (E13).

Além dessas questóes, os entrevistados trouxeram algumas dificuldades enfrentadas no cotidiano de trabalho para lidar com a representação social do câncer dos pacientes e familiares, como notado na seguinte fala:

[...] O desconhecimento, às vezes, acerca da doença. Ou mesmo o estigma, que a doença te traz [...] as pessoas acham que já tá decretado que ela vai morrer, então isso é um dificultador muito grande [...] (E6).

Além disso, pôde-se identificar que, no cotidiano dos enfermeiros, existe dificuldade em lidar com os sentimentos advindos da aproximação, criação de vínculo e apego aos pacientes, o que pode ser verificado a seguir:

[...] muito carinho, muita estima pelo paciente [...] você se aproxima muito e você acaba tendo dificuldade [...] principalmente quando esse paciente tem um agravamento da doença ou vem a óbito [...] (E6); [...] que eu não gosto de ter contato, pra eu não saber, não sofrer. Não que eu seja fria, é o meu jeito de ser para não sofrer, porque eu sou muito apegada as coisas, então se eu ficar sabendo, quando o paciente veio, que que o paciente é, a família, onde mora [...] eu fico triste, porque eu não quero perder o paciente, entâo eu sofro [...] (E8).

Também foi constatado que situaçôes que remetem a questóes de cunho pessoal dos profissionais entrevistados causam sofrimento, pois eles se colocam no lugar do paciente e se imaginam naquela situação, o que mostra a fala a seguir:

[...] já peguei uma menina de 30 anos também, ela era técnica de enfermagem e ela tinha descoberto o câncer de mama, entáo tudo muito próximo de mim, tinha um filho pequeno da idade do meu filho [...] $\mathrm{e}$ isso me remeteu muito à minha vivência, à minha vida pessoal e à minha vida profissional. Entáo isso me machucou, eu chorei com ela [...] (E7).

Por outro lado, o cotidiano do trabalho na Oncologia foi descrito por alguns profissionais entrevistados como positivo, por despertar sentimentos como gratificaçáo, empatia e carinho pelo próximo, o que pode ser evidenciado nas falas a seguir:

[...] é estressante, é cansativo, mas, ao mesmo tempo, muito gratificante, porque às vezes a família perde uma pessoa querida, mas ela vem e dá um abraço, agradece todo carinho que você teve com a pessoa nos últimos dias de vida (E1); [...] é muito gratificante [...] quando você vê pessoas conseguindo, se não a cura, mas pelo menos uma qualidade de vida (E6); [...] a gente cria muita empatia, tanto com a família do paciente quanto com o paciente (E1).

Pôde ser verificado também que o trabalho na Oncologia ressignifica a vida e os valores pessoais desses profissionais, fazendo com que eles passem a enxergar o mundo de uma forma diferente, reclamar menos da vida e procurar ver o lado positivo de todas as situaçôes vivenciadas, o que pode ser visto nos seguintes depoimentos:

[...] eu tento ver o lado positivo de tudo, porque pra frente a gente vê que tem muita gente sofrendo demais aqui (E2); [...] eu nunca vou me esquecer de uma paciente que um dia chorou ao ver o sol! Olha o sol lá fora! [...] então a gente aprende a ser mais humano, a gente aprende a dar valor a pequenas coisas (E9).

Os depoimentos supracitados sinalizam que o cuidado em Oncologia despertou nos profissionais de Enfermagem experiências que tocam sua vida profissional e pessoal, construindo um conjunto de competências profissionais inerentes a essa especialidade.

\section{COMPETÊNCIAS PROFISSIONAIS DO ENFERMEIRO QUE ATUA NA ONCOLOGIA}

Essa categoria revela que os enfermeiros que atuam no cuidado oncológico devem apresentar em seu perfil atitudes e valores como força, sensibilidade, determinação e maturidade, conforme ilustram os depoimentos a seguir:

[...] acho que o principal aspecto assim é ao mesmo tempo a sensibilidade com o paciente e a força para lidar com ele (E3); [...] ele precisa ser forte, ser uma pessoa determinada, saber que ele quer estar aqui (E5); [...] maturidade, para estar lidando com os fatos dos pacientes que são terminais, com a morte (E13).

Outras competências profissionais requeridas ao enfermeiro no processo de cuidar em Oncologia na visão dos entrevistados são empatia, paciência, carinho, capacidade para apoiar e oferecer acolhimento e conforto 
ao paciente e seus familiares, além de saber trabalhar seu lado emocional de forma a não ter sofrimento psicológico diante dos desafios cotidianos, conforme ilustram os depoimentos a seguir:

[...] ele precisa ser uma pessoa que tem empatia, gostar de outras pessoas, porque as pessoas oncológicas, elas precisam muito de apoio, precisam muito de uma palavra amiga (E5); [...] ter mais paciência, o lado psicológico tem que ser mais fortalecido, ele tem que ser completamente humano [...] (E7); [...] a diferença é a parte psicológica [...] não que a gente se torna mais duro, mas a gente se torna mais seletivo nas emoçóes que a gente vai absorver ou não (E6).

Além disso, os relatos de alguns entrevistados mostraram que esse profissional deve ser apto a separar a vida pessoal da vida profissional, como evidenciado a seguir:

[...] a gente tem que vir sempre com a mente preparada [...] os problemas que a gente tem na vida da gente sempre ficam da porta do serviço para fora. A gente tem saber separar muito bem [...] (E11).

\section{SUPERAÇÕES COTIDIANAS E FORMAS DE ENFRENTAMENTO DOS ENFERMEIROS NA PRÁTICA ASSISTENCIAL EM ONCOLOGIA}

Os resultados dessa categoria trouxeram alguns desejos de superaçóes dos enfermeiros diante de situaçóes vivenciadas na prática assistencial ao paciente oncológico, evidenciados pelos relatos dos participantes que revelaram questôes de cunho emocional, como se envolver menos com os pacientes, superar fraquezas e sentimentos de incapacidade, assim como os desafios diários da Oncologia, conforme expressam as falas:

[...] eu queria me envolver menos com os pacientes, emocionalmente (E1); [...] eu queria muito superar esse sentimento de incapacidade, quando você se pega numa situaçáo que você náo tem o que fazer [...] (E4); [...] eu acho que todo dia você tem que superar os desafios que aparecem, todos os dias vão ser desafios diferentes e que mexem com $\mathrm{o}$ sentimento [...] (E2).

Notou-se também o anseio dos enfermeiros em superar suas dificuldades de lidar com pacientes pediátricos, em que a maioria dos entrevistados demostrou resistência em aceitar o adoecimento e morte desses pacientes, além de náo conseguirem desvincular a vivência pessoal de ser ter um filho criança, da vivência profissional de ter que lidar com pacientes da mesma idade que seus filhos, constatado nas seguintes falas:
[...] a gente vivenciar e ver que o adulto tá em término de vida, é mais fácil do que quando relacionado à criança. A gente imagina que criança tá boa, tem toda vida pela frente, então é mais difícil [...] (E2); [...] então, quando vem criança pra cá, a gente fica mal, a gente fica questionando: Por que uma criança tem essa doença? Por que uma criança tão inocente está sofrendo? (E9); [...] toda vez que penso na pediatria, vem a minha filha [...] é uma coisa que eu ainda quero trabalhar [...] ainda não consegui superar esse ponto (E6).

Outro aspecto identificado nas entrevistas foi que cada profissional enfrenta, de modo diferente, as situaçóes desafiadoras encontradas em seu cotidiano, evidenciado pelos depoimentos, que trouxeram questôes como se manter mais afastado e náo se envolver afetivamente com o paciente e seus familiares, mostrados nas seguintes falas:

[...] a gente tenta ficar mais afastado, você sabe que se você chegar muito perto você vai acabar se apegando (E1); [...] A gente tenta não se apegar tanto e lidar mais profissionalmente possível, pra gente nấo sofrer tanto, porque é inevitável (E1).

Por outro lado, os depoimentos trouxeram formas de enfrentamento apresentadas pelos enfermeiros para lidar com as adversidades inerentes ao trabalho, como o apoio da equipe de trabalho e da família, a busca de suporte na religião, a prática de atividades físicas e terapia, demonstradas nos depoimentos a seguir:

[...] o trabalho em equipe mesmo que mais ajuda (E1); [...] são muitas atividades recreativas que a gente precisa fazer, atividade física, bom relacionamento com os familiares, é basicamente aquilo que te desestressa, todo mundo tem uma válvula de escape específica (E3); [...] eu tento enfrentar através mesmo da oração (E7); [...] eu faço terapia. Entáo, assim, eu tenho uma carga emocional alta, aí eu despejo literalmente junto com minha terapeuta (E12).

Constatou-se ainda nos relatos dos entrevistados que o tempo de trabalho na Oncologia auxilia no enfretamento das dificuldades cotidianas, podendo ser visualizado na fala a seguir:

[...] hoje em dia a gente já enfrenta melhor né, depois de uns anos que a gente começa a trabalhar né, a gente já começa a enfrentar melhor [...] você acaba tendo que se acostumar com esse tipo de situação, porque é muito frequente (E4). 
Outros depoimentos mostraram que outra forma de enfretamento desses profissionais é buscar mais conhecimento sobre a patologia e seu prognóstico, evitando assim situaçóes inesperadas e consequentemente sofrimento ao profissional, como verificado a seguir:

[...] mecanismo para não deixar isso não me afetar no início é entender um pouco mais sobre o que é a doença e quais são os prognósticos dela (E6); [...] eu estudo muito! Entáo eu procuro estar sempre informado do que aquela doença pode causar para aquele paciente (E12).

Além disso, foi verificado nas entrevistas que o reconhecimento do profissional de ter feito tudo o que podia para o paciente e aceitar os desfechos de cada caso assistido foram relatados pelos enfermeiros como importante mecanismo que auxilia no enfrentamento dos desafios diários do trabalho, evidenciado no depoimento a seguir:

[...] ver que não teve jeito né, eu fazia tudo o que eu podia e náo podia, e acabou que no final ele faleceu, eu sofri muito com a perda dele, mas é uma coisa que a gente passa por isso e náo tem muito o que fazer (E4); [...] você pensa que fez o que pôde [...] quando vem um momento difícil, é importante você estar com a consciência limpa [...] (E5).

Pôde-se perceber também que essa forma de enfrentamento supracitada ora se desdobra em sentimento de dever cumprido, ora em sentimento de autocobrança, que gera sobrecarga, cansaço e estresse no cotidiano laboral por parte do profissional, constatado nas falas que seguem:

[...] é um sentimento de dever cumprido, de que você conseguiu fazer algo diferencial pra aquele paciente [...] (E1); [...] quando consigo resolver, só que tem hora que eu náo consigo, [...] eu fico pensando aqui, como eu faço? E se eu tivesse feito diferente? E se eu tivesse feito aquilo? [...] já chorei aqui de raiva, chorei, raiva assim, por não ter conseguido atingir o que eu queria (E10).

\section{DISCUSSÃO}

Uma das questôes que permeiam o cuidado em Oncologia é a criação de vínculo entre enfermeiros, pacientes e familiares, viabilizado pelo longo período de tempo em que os profissionais permanecem junto a esses indivíduos no processo de cuidado, empreendendo açôes no momento do diagnóstico, do tratamento, da reabilitação e dos cuidados paliativos. Sendo assim, são exigidas do enfermeiro que atua em Oncologia habilidades relacionais e afetivas, que, muitas vezes, se tornam um desafio na prática profissional cotidiana.

Nesse sentido, os resultados deste estudo reforçam as evidências existentes sobre a grande complexidade da assistência ao paciente oncológico ${ }^{12}$, visto que alguns participantes do estudo qualificaram o cotidiano de trabalho nessa área como desafiador, pesado, maçante, estressante e carregado de sofrimento.

Estudo realizado na cidade de São Paulo, que buscou compreender o significado que o enfermeiro atribui à ação de cuidar em Oncologia, caracterizou o cotidiano de trabalho nessa área como cansativo e exaustivo. Ainda revelou sentimentos experenciados pelos enfermeiros como sofrimento, impotência, revolta e sobrecarga de trabalho ${ }^{13}$, corroborando alguns achados do presente estudo, em que os participantes também trouxeram relatos de um cotidiano estressante, cansativo e pesado e referiram sentimentos como sofrimento e impotência.

Por outro lado, o reconhecimento e a valorização do trabalho ofertado geram uma satisfação na equipe de enfermagem ${ }^{14}$, indo ao encontro dos depoimentos que caracterizam o cotidiano como gratificante, conforme verificado na primeira categoria.

Outro aspecto que caracterizou a prática profissional do enfermeiro na Oncologia, na visão dos entrevistados da presente pesquisa, foi a dificuldade dos profissionais em lidar com as representaçôes sociais e estigmas do câncer trazidos pelos pacientes e seus familiares. Percebe-se que, apesar de a assistência às pessoas com câncer ter avançado ao longo dos anos, o termo câncer ainda é evitado por muitas pessoas ${ }^{15}$. Estudo aponta que o câncer, por ser uma doença estigmatizada, coloca os indivíduos e seus familiares em condiçáo de fragilidade pelo próprio diagnóstico da doença, sendo responsável pelo afastamento do doente dos seus papeis sociais e, até mesmo, desistência do tratamento por acreditar na impossibilidade da $\operatorname{cura}^{16}$.

Ademais, essa pesquisa aponta que quanto maior o conhecimento da família sobre o diagnóstico e tratamento do câncer, melhor é a qualidade do cuidado prestado, cabendo assim, à equipe de saúde e enfermagem, a responsabilidade de orientar a família e o paciente sobre os aspectos referentes ao tratamento oncológico, sendo fonte de suporte e amparo, e, assim, minimizar os estigmas referentes à doença ${ }^{17}$.

Ainda na primeira categoria, pôde-se perceber que os enfermeiros entrevistados relataram dificuldades em sua prática profissional relacionadas a como lidar com $\mathrm{o}$ vínculo emocional estabelecido com os pacientes e familiares, com a terminalidade da vida, além das situaçóes vivenciados no trabalho que remetem à vida pessoal desses profissionais. Esses resultados corroboram os achados de outros estudos que revelam situaçóes desafiadoras no 
cotidiano de trabalho em Oncologia, decorrentes dos dilemas éticos e morais que incidem sobre as decisóes de tratamento, doenças, perda e morte prematura dos pacientes e gestão de fronteiras profissionais no que diz respeito às relaçóes com os pacientes e seus familiares, chegando ao pressuposto que tais situações podem levar os profissionais a mudarem de especialidade ou até mesmo de carreira ${ }^{4}$.

Tais repercussóes na vida do profissional podem ser relacionadas a lacunas referentes ao processo formativo, que náo prepara o enfermeiro para a vivência de situaçóes que exigem habilidade emocional e manejo do sofrimento diante da finitude da vida, visto que a formação ainda está muito centrada no modelo curativista ${ }^{18}$.

Outro estudo corrobora essa questão, ao afirmar que, quando a cura já não faz mais parte do prognóstico, os profissionais percebem o processo de terminalidade e a morte, tão comuns em doenças crônicas diagnosticadas em estágio avançado, como o câncer, como um incômodo que desafia os saberes profissionais, por crerem na cura como finalidade única, e a crença na onipotência da tecnologia como dificultadores para o enfrentamento de tais situaçóes ${ }^{17}$. Tal situação gera sentimento de impotência, frustação, insegurança e até mesmo depressão, aspectos estes que também estiveram presentes nos depoimentos dos entrevistados do presente estudo ${ }^{19}$.

Os achados da segunda categoria evidenciam competências essenciais ao enfermeiro que atua na Oncologia, delineando um perfil profissional específico dessa especialidade. Pesquisa com o objetivo de compreender a natureza da interação entre enfermeiro e doentes oncológicos trouxe como atributos essenciais de um enfermeiro o desenvolvimento de sentimentos como preocupação, empatia, facilitação, genuidade com o outro ${ }^{20}$, corroborando os achados deste estudo, em que os participantes manifestaram sentimentos como empatia, realização profissional, carinho pelo próximo, entusiasmo e motivação no desenvolvimento do trabalho.

Nesse sentido, o cotidiano de trabalho na Oncologia, caracterizado por muitos autores como complexo, exige competências profissionais que integrem saberes essenciais para lidar com os desafios que o paciente oncológico apresenta, exigindo conhecimentos, habilidades e atitudes que contemplem os quatro pilares das competências requeridas dos profissionais de saúde, sendo eles: saber ser, saber conviver, saber conhecer e saber fazer ${ }^{21}$.

$\mathrm{O}$ saber ser refere-se às atitudes dos profissionais baseadas nos seus princípios e crenças e seu modo de perceber e viver o mundo; o saber conviver diz respeito às atitudes pessoais e habilidades que facilitam a convivência e o trabalho em equipe; enquanto o saber conhecer se refere aos conhecimentos teóricos específicos de cada profissional; e, por fim, as competências relacionadas ao saber fazer referem-se ao conjunto de habilidades, sejam elas cognitivas, emocionais ou sociais, que permitem ao indivíduo aplicar o conhecimento na sua prática ${ }^{7}$.

Nesse sentido, conforme analisado nas falas dos participantes, as atitudes profissionais como força, sensibilidade, determinação, maturidade, resiliência, empatia, paciência, carinho, capacidade para apoiar e oferecer conforto ao paciente e seus familiares, entre outras, que remetem a questóes atitudinais e de valores, se referem ao saber ser; enquanto competências como saber trabalhar em equipe e ter bom relacionamento com a família condizem com o segundo pilar, saber conviver. Ainda em consonância com os achados deste estudo, ao relatarem a busca constante por aprimoramento e a necessidade de conhecimento técnico específico, condizem com os pilares saber e saber fazer, sequencialmente, nos quais se infere que um profissional que atua na Oncologia deva possuir competências nos quatro eixos considerados essenciais na formação do perfil profissional.

Vale ressaltar que a construção da identidade do enfermeiro vai além dos conhecimentos teóricos e técnicos adquiridos durante sua formação, uma vez que ela se dá também pela união dos elementos objetivos e subjetivos que compóem o mundo do trabalho, que, ao produzir seus efeitos na esfera do cotidiano, afetam e se fazem sentir pelo trabalhador, imprimindo-lhe marcas. Nesse sentido, o enfermeiro aprende a mobilizar, a integrar e a transferir o conhecimento para a prática, desenvolvendo suas habilidades ${ }^{15}$.

Posto isso, foi considerado para o presente estudo o conceito de cotidiano utilizado pelo filósofo Maffesoli, que o considera não apenas como sinônimo de dia a dia, mas também, como forma de se expressar a maneira de viver determinados contextos, integrando as cenas do viver e do conviver. Na área da saúde, o cotidiano é visto por esse autor como a maneira de viver dos seres humanos, levando em consideração suas crenças, valores, significados, que vão desenhando o processo de viver do indivíduo ${ }^{21}$.

Nesse sentido, esse conceito expressa o cotidiano laboral do enfermeiro na Oncologia, permeado por múltiplas questóes desafiadoras, que se transformam em uma espiral de afetos, sentimentos, angústias, incertezas e (re)significaçóes, em um constante movimento de buscas e associaçôes entre a vida pessoal-profissional, conformando uma práxis que transcende o espaço físico e as habilidades técnicas.

Em relação à terceira categoria, alguns desejos de superaçóes foram citados pelos participantes desta pesquisa, relacionados a um desejo de manejo mais adequado de questóes de cunho emocional, como se envolver menos com os pacientes, superar fraquezas e 
sentimentos de incapacidade, assim como saber lidar com os desafios diários da Oncologia. Cabe ressaltar que a maioria dos entrevistados demostrou anseio em superar as dificuldades de lidar com pacientes pediátricos.

Estudo sobre neoplasias pediátricas revelou que situaçôes estressoras aos profissionais de saúde dessa área vão além do sofrimento, complicaçóes e morte causadas pela doença. Há uma percepçáo da incompatibilidade dessas doenças com a infância, uma vez que o câncer pode interromper uma vida que estava apenas se iniciando, privando a criança do desenvolvimento do seu ciclo vital ${ }^{17}$.

Todas as necessidades de superaçôes frente aos desafios da prática oncológica referenciadas pelos enfermeiros do presente estudo sinalizam para a importância das estratégias de enfrentamento para manutenção do bem-estar físico, psicológico e espiritual desses profissionais. Entre estas, ganham destaque a construção e o desenvolvimento de novos marcos conceituais na assistência, como a resiliência ${ }^{22}$.

Neste estudo, o processo de enfrentamento é entendido como esforços comportamentais e cognitivos utilizados pelo indivíduo para conduzir um acontecimento estressante. Por não garantir a solução do problema, é necessário que o indivíduo seja resiliente, o que resulta em ações de confronto e superação ${ }^{23}$.

Na perspectiva psicossocial, que será considerada para efeitos do presente estudo, a resiliência pode ser definida como a habilidade que as pessoas ou grupos possuem de responder, de forma mais consistente, aos desafios e às dificuldades, com capacidade de recuperação diante de circunstâncias desfavoráveis, sem perder o equilíbrio inicial; ou seja, com capacidade de se adaptar e reequilibrar constantemente ${ }^{24}$.

Corroborando os achados deste estudo, alguns autores discorrem sobre a dificuldade de cuidar das pessoas com câncer, surgindo a necessidade de desenvolver estratégias de enfretamento, visto que, à medida que se lança mão delas, o indivíduo consegue reavaliar sua condição física e emocional em relação ao fator estressante e criar formas eficazes de enfretamento para serem utilizadas em situaçôes futuras ${ }^{15-25}$.

Neste estudo, foram encontradas diferentes formas de enfrentamento relatadas pelos enfermeiros que atuam na Oncologia; entre elas, destaca-se o apoio da equipe de trabalho, da família, da religiáo, a realizaçáo de atividades físicas, fazer terapia, além do tempo de experiência na área e aprimoramento profissional acerca da doença e seu prognóstico.

Estudo com o objetivo de conhecer as estratégias que os enfermeiros utilizam para lidar as situaçóes advindas do processo de cuidado de paciente oncológicos evidenciou a importância do trabalho em equipe e a busca espiritual como formas de minimizar o sofrimento causado no cotidiano do cuidar, sendo esses resultados consoantes com alguns dos achados da presente pesquisa ${ }^{26}$.

Além dessas, alguns participantes referiram, como formas de enfretamento, manterem-se o mais afastado possível do paciente, com o intuito de não se apegar, além de tentarem separar a vida pessoal da vida profissional. $\mathrm{O}$ estudo verificou que, apesar de os enfermeiros terem como foco a manutençáo de um certo distanciamento entre eles e os pacientes e seus familiares, esse ato acaba reverberando nas ações do cuidado, desqualificando-as e limitando-as ${ }^{15}$. Além disso, ao reagirem dessa forma, entende-se que exista uma inabilidade de exercer a resiliência, expressa por alguns entrevistados no seu processo do cuidado oncológico, o que pode dificultar a execução do trabalho e ainda ser fonte de sofrimento emocional para eles diante das situaçōes que vivenciam.

Os resultados apresentados na primeira categoria apontaram que os sentimentos despertados pelo trabalho na Oncologia, como culpa, tristeza, frustração, somados aos depoimentos que revelam as tentativas de náo se apegar ao paciente, identificadas na terceira categoria, evidenciam que muitos profissionais, intencionalmente ou não, acabam por exercer um cuidado que se distancia da humanização. Este pode ser caracterizado pela desatenção às necessidades dos pacientes e familiares, cujo foco se dá somente nos aspectos técnicos do cuidar, evidenciado por atitudes que mostram fuga às perguntas dos pacientes ou atitudes que demonstram que os profissionais não buscam conhecer suas histórias para não sofrer, confirmando a ausência da competência da resiliência nesses profissionais, e ainda dificuldades no manejo de situaçôes referentes ao adoecimento crônico, ao processo de morte e ao morrer.

Em contrapartida, as falas que demostram força para lidar com as situaçóes difíceis, aceitação do prognóstico do paciente, estar consciente de ter proporcionado o melhor cuidado ao paciente, indicam o desenvolvimento de competências atitudinais importantes no que se referem às demandas de cunho emocional, interpessoal e afetivo apresentadas pelo paciente.

Além disso, ao analisar as falas dos entrevistados desta pesquisa, pode-se inferir que a resiliência está diretamente relacionada com o tempo de trabalho na área, e que ela pode ser aprendida e desenvolvida pelos profissionais no decorrer da vida profissional dos entrevistados. Segundo estudo, a resiliência é entendida como uma tendência que se manifesta diante da necessidade de superar uma situação de risco e assegurar a continuidade de um desenvolvimento saudáve ${ }^{27}$. Essa afirmativa vai ao encontro de autores que consideram a resiliência como uma competência pessoal e social que pode ser aprendida, promovida ou aprimorada nas pessoas, nas organizaçóes e nas comunidades, por 
meio de práticas cognitivas transformacionais, educação e apoio ambiental.

Sendo assim, a resiliência pode ser utilizada para facilitar as ações da Enfermagem, propiciando mudanças pessoais e melhorias nas relaçóes de trabalho e, consequentemente, garantindo ao paciente uma melhor qualidade nas atividades prestadas por esses profissionais ${ }^{28}$.

\section{CONCLUSÃO}

Esta pesquisa mostrou que o cotidiano de trabalho na Oncologia gera distintos significados para os profissionais da área, que vão desde realização profissional e motivação, até um cotidiano complexo, permeado de sentimentos negativos e difíceis que ainda precisam ser superados e trabalhados por esses profissionais.

Além disso, este estudo evidenciou algumas competências indispensáveis ao enfermeiro que atua em Oncologia, contempladas nos eixos saber ser, saber conviver, saber fazer e saber conviver junto. Esse perfil aponta para a necessidade constante de busca de conhecimentos e do aprimoramento profissional, com vistas a um melhor manejo dos desafios e dificuldades relativas ao processo de cuidar em Oncologia.

Nesse sentido, desenvolver a resiliência torna-se uma importante estratégia de auxílio aos enfermeiros, no intuito de lidar melhor com o processo saúde-doença-adoecimento dos indivíduos e das famílias que eles assistem, contribuindo para a promoção de um cuidar de qualidade, e para a construção de ambientes de trabalho mais flexíveis e saudáveis.

Portanto, os resultados deste estudo trazem reflexôes e desdobramentos importantes para a área de ensino em saúde e na Enfermagem, (re)conduzindo um novo olhar à formação de profissionais de saúde para além das competências técnicas, e sinalizando para a relevância da formação centrada em competências humanas e relacionais, indispensáveis ao processo de trabalho no âmbito da Oncologia.

Este estudo traz como limitaçóes o fato de não ter abordado o processo de formação dos enfermeiros, o que poderia permitir a realização de correlações interessantes entre as dificuldades vivenciadas na prática ante os desafios do cotidiano de trabalho na Oncologia e o desenvolvimento de competências. Sugere-se a realização de novos estudos nessa temática.

\section{CONTRIBUIÇÕES}

Todos os autores contribuíram substancialmente na concepção ou no planejamento do estudo, na obtenção, na análise e/ou interpretação dos dados, assim como na redação e/ou revisão crítica e aprovaram a versão final a ser publicada.

\section{DECLARAÇÃO DE CONFLITOS DE INTERESSES}

Nada a declarar.

\section{FONTES DE FINANCIAMENTO}

Não há.

\section{REFERÊNCIAS}

1. Instituto Nacional de Câncer José Alencar Gomes da Silva. Estimativa 2018: incidência de câncer no Brasil [Internet]. Rio de Janeiro: INCA; 2017 [acesso 2019 dez. 17]. Disponível em: https://www.inca.gov.br/sites/ ufu.sti.inca.local/files//media/document//estimativaincidencia-de-cancer-no-brasil-2018.pdf/

2. Kolhs M, Machri E, Ferri G, et al. Sentimentos de enfermeiros frente ao paciente oncológico. J Health Sci. 2016;18(4):245-50.

3. Almeida CSL, Sales CA, Marcon SS. O existir da enfermagem cuidando na terminalidade da vida: um estudo fenomenológico. Rev Esc Enferm USP. 2014;48(1):34-40. doi: http://dx.doi.org/10.1590/ S0080-623420140000100004

4. Bordignon M, Monteiro MI, Mai S, et al. Satisfação e insatisfação no trabalho de profissionais de enfermagem da oncologia do Brasil e Portugal. Texto Contexto Enferm. 2015;24(4):925-33. doi: http://dx.doi. org/10.1590/0104-0707201500004650014

5. Lima PC, Comassetto I, Faro ACM, et al. O ser enfermeiro de uma central de quimioterapia frente à morte do paciente oncológico. Esc Anna Nery. 2014;18(3):503-09. doi: http://dx.doi.org/10.5935/1414-8145.20140071

6. Ministério da Educação (BR), Conselho-Nacional de Educação, Câmara de Educação Superior. Resolução CNE/CES no 3, de 7 de novembro de 2001. Diretrizes Curriculares Nacionais do Curso de Graduação em Enfermagem. Diário Oficial da União, Brasília, DF; 2001 nov. 9. Seção I, p. 37.

7. Cotta RMM, Costa GD, Mendonça ET. Portfólios crítico-reflexivos: uma proposta pedagógica centrada nas competências cognitivas e metacognitivas. Interface (Botucatu). 2015;19(54):573-88. doi: http://dx.doi. org/10.1590/1807-57622014.0399

8. Minayo MCS, organizadora. Pesquisa social: teoria, método e criatividade. 34. ed. Petrópolis, RJ: Editora Vozes Limitada; 2011.

9. Fundação Cristiano Varella. História [Internet]. Muriaé, MG: Hospital do Câncer de Muriaé; [2000] - [acesso 2017 maio 30]. Disponível em: http://www.fcv.org.br/ site/conteudo/detalhe/87 
10. Fontanella BJB, Luchesi BM, Saidel MGB, et al. Amostragem em pesquisas qualitativas: proposta de procedimentos para constatar saturação teórica. Cad Saúde Pública. 2011;27(2):389-94. doi: http://dx.doi. org/10.1590/S0102-311X2011000200020

11. Bardin L. Análise de conteúdo. São Paulo: Ediçôes 70; 2016.

12. Oliveira JM, Reis JB, Silva RA. Busca por cuidado oncológico: percepção de pacientes e familiares. Rev Enferm UFPE [Online]. 2018;12(4):93846. doi: https://doi.org/10.5205/1981-8963v12i4a231359p938-946-2018

13. Popim RC, Boemer MR. Cuidar em oncologia na perspectiva de Alfred Schutz. Rev Latino-am Enfermagem. 2005;13(5):677-85. doi: https://doi. org/10.1590/S0104-11692005000500011

14. Oliveira AEG, Cury VE. Cuidar em oncologia: uma experiência para além do sofrimento. Memorandum. 2016;31(3):237-58.

15. Luz KR, Vargas MAO, Barlem ELD, et al. Estratégias de enfrentamento por enfermeiros da oncologia na alta complexidade. Rev Bras Enferm. 2016;69(1):67-71. doi: http://dx.doi.org/10.1590/0034-7167.2016690109i

16. Barbosa LNF, Francisco AL. A subjetividade do câncer na cultura: implicaçóes na clínica contemporânea. Rev SBPH. 2007;10(1):09-24.

17. Silva CMM, Silva MPC, Ferreira DO, et al. Significado do cuidar e seus sentimentos para equipe de enfermagem diante da criança em tratamento oncológico. Rev Enferm Atenção Saúde. 2018;7(2):83-94. https://doi. org/10.18554/reas.v7i2.2355

18. Silva MM, Santanda NGM, Santos MC, et al. Cuidados paliativos na assistência de alta complexidade em oncologia: percepção de enfermeiros. Esc Anna Nery. 2015;19(3):460-6. doi: http://dx.doi.org/10.5935/14148145.20150061

19. Silva AF, Issi HB, Motta MGC, et al. Cuidados paliativos em oncologia pediátrica: percepçóes, saberes e práticas na perspectiva da equipe multiprofissional. Rev Gaúcha Enferm. 2015;36(2):56-62. doi: http://dx.doi. org/10.1590/1983-1447.2015.02.46299

20. Lopes MJ. Os clientes e os enfermeiros: construção de uma relação. Rev Esc Enferm USP. 2005;39(2):220-8

21. Nistchke RG, Tholl AD, Potrich T, et al. Contribuiçôes do pensamento de Michel Maffesoli para pesquisa em enfermagem e saúde. Texto Contexto Enferm. 2017;26(4):e3230017. doi: http://dx.doi. org/10.1590/0104-07072017003230017

22. Arrogante O. Resiliencia en enfermería: definición, evidencia empírica e intervenciones. Index de Enferm. 2015;24(4):232-35. http://dx.doi.org/10.4321/S113212962015000300009

23. Rodrigues FSS, Polidori MM. Enfrentamento e resiliência de pacientes em tratamento quimioterápico e seus familiares. Rev. Bras. Cancerol. 2012; 58(4): 619-627. doi: https://doi.org/10.32635/2176-9745. RBC.2012v58n 4.564

24. Tavares J. Resiliência e educação. São Paulo: Cortez; 2001.

25. Lazzaroto PK, Celich KLS, Souza SS, et al. Estratégias de enfrentamento utilizadas pela equipe de enfermagem no cuidado ao paciente oncológico e família. Rev Enferm UFSM. 2018;8(3):560-575. doi: http://dx.doi. org/10.5902/2179769229408

26. Salimena AMO, Teixeira SR, Amorim TV, et al. Estratégias de enfretamento ao cuidar de pacientes oncológicos. Rev Enferm UFSM. 2013;3(1):8-16. doi: http://dx.doi.org/10.5902/217976926638

27. Sousa VFSS, Araujo TCCF. Estresse ocupacional e resiliência entre profissionais de saúde. Psicol ciênc prof. 2015;35(3):900-15. doi: http://dx.doi. org/10.1590/1982-370300452014

28. Quadros A. Resiliência em oncologia: um olhar sobre a práxis do enfermeiro [dissertação]. Rio Grande do Sul: Pontifícia Universidade Católica, Faculdade de Educação; 2012. 